\title{
Bidirectional Work Family Conflict of Expatriates: Framework of Antecedents and Moderators
}

\author{
Tayyaba Zeeshan ${ }^{* 1}$, Farhan Sarwar ${ }^{2}$ \\ ${ }^{1}$ Folsom Lake college, 10 College Pkwy, Folsom, CA 95630 \\ ${ }^{2}$ Universiti Teknologi Malaysia, Johore, Malaysia \\ *Corresponding author: tayyabz02@gmail.com
}

\begin{abstract}
Expatriates work family conflict is one of the least explored areas in expatriate research literature. Applying the conservation of resource model, the current study presents a theoretical framework to understand as to how expatriates' work and non work related challenges like person group fit, person supervisor fit, cultural novelty and spousal adjustment relate to their work family conflict. The study also postulates the possibility of expatriate personality moderating the relationship between work and family domain challenges and the work family conflict.
\end{abstract}

Keywords: Expatriation, Work Family Issues, Conservation of Resources Theory, Personality, Cultural Distance, Person Environment Fit

\section{ARTICLE INFORMATION}

Received:03 ${ }^{\text {rd }}$ Jan 2019

Revised: $10^{\text {th }}$ Feb 2019

Accepted: $15^{\text {th }}$ Feb 2019
The number of multinational corporations (MNCs), operating around the world, has increased manifold over the past few decades. In 1969 , there were only 7,258 known multinationals, by 2009 that number had increased to $82,053 \mathrm{MNCs}$, with more than eight hundred thousand affiliates located in almost every corner of the world (UNCTAD, 2009). Proficient and skilled expatriates are considered the most viable means of enhancing a business's global presence; therefore the rise in the number of MNCs has led to a steady increase in the demand for expatriates(Harvey \& Moeller, 2009). Global Relocation Trends Survey (GRTS, 2011)reported that, $61 \%$ of the MNCs included in the annual survey expected an increase in the number of their expatriate employees in the year 2011. Due to the rapidly increasing globalization trend, the expatriate assignments today have gained a lot of strategic importance (Cheong, Sandhu, Edwards, \& Poon, 2018; Sánchez Vidal, Sanz Valle, \& Barba Aragón, 2008; Stroh, Black, Mendenhall, \& Gregersen, 2004). MNCs need proficient expatriates for the successful running of their foreign operations. Considering the strategic importance of expatriate assignments MNCs endeavor to assess and select most suitable employees to send on international assignments (Caligiuri, Tarique, \& Jacobs, 2009; Harvey \& Moeller, 2009). But these assignments prove to be more often than not a turbulent time for expatriates, as they bring about changes in the two main spheres of their lives, their work and family (Shaffer, Harrison, Gilley, \& Luk, 2001). A latest survey shows that $70 \%$ of the expatriates were married, another $7 \%$ were in a serious relationship, and $47 \%$ were accompanied by children (GTRS, 2010)According to Lazarova, Westman, and Shaffer (2010) expatriate assignments act as mechanism of change in work as well as family lives of expatriates, and expatriates strive to find a new balance between their work and family roles. At work, expatriates have to deal with a new work environment and a new work role with an increased pressure to perform. In the family domain, expatriates encounter issues like cultural adaptability, spouse's career and adjustment problems (Van der Zee, Ali, \& Salome, 2005).

Furthermore at the time when expatriate are exposed to challenging demands in both work and family domains, they get cut off from one of their most important resource: social support. This whole scenario makes expatriates a more than likely candidates for experiencing work family conflict (I. C. Fischlmayr \& I. Kollinger, 2010; Mäkelä, Lämsä, Heikkinen, \& Tanskanen, 2017). Work family conflict is defined as : a form of inter role conflict in which the role pressures from the work and family domains are mutually incompatible in some respect. That is participation in the work (family) role is made more difficult by virtue of participation in the family (work) role (Greenhaus \& Beutell, 1985). Work family conflict is known to have two distinct directions work to family interference: work to family interference ( $\mathrm{W} \rightarrow \mathrm{F}$ conflict) and family to work interference $(\mathrm{F} \rightarrow \mathrm{W}$ conflict), with $\mathrm{W} \rightarrow \mathrm{F}$ conflict originating from work domain and $\mathrm{F} \rightarrow \mathrm{W}$ conflict having its antecedents in the family domain. It is well established that both these direction affect the physical as well as psychological well being of an individual, expatriate or not, and have a negative influence on their performance, withdrawal cognitions, and job and life satisfaction (Mäkelä et al., 2017; Van der Zee et al., 2005)According to an Expatriate Work-Life Balance Survey almost two third of the expatriates surveyed reported feeling the strain of managing the competing demands of work and family. It was also ascertained that though $79 \%$ of the MNCs surveyed recognized the importance of work life balance and had devised policies to encounter the problem, almost three-quarters of the expatriates surveyed felt that their organizations were not doing enough to help alleviate the causes of work family conflict/imbalance (ORC Worldwide 2007). We believe that the reason most expatriates deem that their companies are not doing enough to help them overcome issues regarding their work life balance is the lack of research in the said area. According to Heraty, Morley, and Cleveland (2008) there is evidence of "systematic omissions" about work family interface in expatriate research. One cannot device effective policies to deal with a problem, without an in depth research and consequent understanding of the causes of the problem. Although extensive research is available on the antecedents of work family conflict, but most of it is related to individuals working in their home 
countries. The research on the antecedents of work family conflict of expatriates is at its minimal. One cannot fully rely on the domestic work family conflict research while dealing with expatriates because expatriates face many issues like cultural novelty, spousal adjustment, trying to fit in the new group and new work environment; issues that employees working in their home countries usually do not have to encounter (Harrison, Shaffer, \& Bhaskar-Shrinivas, 2004). We believe it is imperative to take into account the effect that these challenges may have on the work family conflict of expatriates, only then we will be able to form and implement work life balance policies that can help expatriates in reducing the conflict. The present study thus investigates the probable antecedents of work family conflict of expatriates in accordance with the conservation of resource (COR) model (Hobfoll, 1989). It presents a theoretical framework which is an extension of the existing studies on work family conflict, and work and non-work related issues of expatriates. Based on the framework the study gives a number of propositions as to how certain changes and challenges in the lives of expatriates can result in an increased work family conflict and how expatriates with certain personal traits are better equipped to deal with the challenges of expatriation than the others.

\section{ISSUES OF EXPATRIATES}

There is a general consensus among researchers that work and family, the two most vital domains of an individuals' life, are heavily interlinked and dependent on each other(Y. Huang, Hammer, Neal, \& Perrin, 2004). The advent of women in the work force resulting in a sharp increase in the number of dual career couples and the growing number of single parents in the labour force have over the years heightened interest in the work-family interface (Whitehead, 2008), and the number of studies investigating the issues regarding work life balance of employees is on the increase. Apart from the dual career couples and single parent families, another group of people who are more than likely to experience work life balance issues that can lead to work family conflict are the expatriates (Brynningsen, 2009; Cuizon, 2009; I. Fischlmayr \& I. Kollinger, 2010; Zeeshan, 2010). Most of the research on the work and family interface of expatriates is related to their work, general and interaction adjustment. Adjustment of expatriates is described as them feeling comfortable with their new work and general environment, and has been found to be related to the withdrawal cognitions of expatriates. There are not many studies which explore the issue of work family conflict or work life imbalance of expatriates, which arise due to the incompatibility of the demands and resources. Table 1 gives a list, though not exhaustive, of the major studies done so far to understand the work family conflict of expatriates.

An examination of the major studies done so far to understand the work family conflict of expatriates, as mentioned in the detailed though not exhaustive list in table 1 shows that most of them agree that expatriate are prone to face work family conflict which has many negative repercussions such as early withdrawal cognitions, decline in mental and physical wellbeing, and performance. However what is missing in most of these studies is the examination of the relationship between expatriate specific challenges and issues and the two directions of the conflict. Shaffer, Harrison, and Joplin (2004) investigated the relation expatriate specific antecedents of work family conflict of expatriates, and found that cultural novelty and spousal adjustment were strongly correlated to work family conflict of expatriates. However the two concerned variables did not emerge as significant contributors in the regression analysis predicting work family conflict. We believe this being the lone study of its kind, leave much to be explored. In the later section we discuss the concept of cultural novelty and spousal adjustment in detail with regard to work family conflict of expatriates, and also examine as to how expatriate personality may influence the relationship between stress of high cultural novelty and spousal maladjustment and the work family conflict of expatriates.
Moreover, while looking for antecedents of WF conflict, studies done so far have restricted them mostly to time related issues like number of hours worked, business travel, and leisure time. Expatriates join a new group and have to deal with a new supervisor in their host country, and thus can surely face the issues of person-group (PG) and person-supervisor (PS) fit, two dimensions of the concept of personenvironment (PE) fit. PG and PS fit depict the compatibility between the goals, personality and values of the new comer and his new group and supervisor that influences their social integration (Kristof-Brown, Zimmerman, \& Johnson, 2005). We understand that PE fit issues cannot be exclusively linked to the expatriates as any individual joining a new company or group can face them, but we believe that these issues will be more pronounced in expatriates because of the national cultural undercurrents having a significant effect on the values and working practices of the host country's group members and the supervisor. According to Hofstede, people carry "mental programs" that are initially developed in early childhood in the family, and are later reinforced in their schools, and society. These programs contain a component of national culture, and are expressed in the difference of values among people from different countries. Culture in this sense is a system of collectively held values. Hofstede (1983) found that, employee's values show steady differentiation between countries; employee of a particular country has a different set of values than employee of another country. Keeping in view this discussion PG and PS fit are seen as distinctive issues related to expatriation, and their affects on work family conflict are discussed in detail later in accordance with the conservation of resource theory; the underlying theory of the current paper.

\section{CONSERVATION OF RESOURCE MODEL}

There are a number of theories presented and applied to fully comprehend the antecedents and outcomes of the work family conflict, such as role theory, social exchange theory, ecosystem theory, conservation of resources theory and border/boundary theory. However it is widely recognized that roots of the work family conflict lie in the role theory (Frone, 2003). According to the role theory, conflict arises when individuals engage themselves in multiple roles whose demands are incompatible with each other (Kahn, Wolfe, Quinn, Snoek, \& Rosenthal, 1964). The present study relies on conservation of resource (COR) theory to explore and understand the work family conflict of expatriates. In context of work family conflict COR theory is considered as an enhancement over the role theory, which does not specify moderators that may influence the relationship between work and family role stressors and the conflict itself.

Conservation of resources (COR) theory presented by Hobfoll (1989) is an integrated model encompassing various theories of stress. COR theory is established on the credence that all individuals strive to retain and acquire resources, and are threatened by the probable or actual loss of these resources. The resources recognized by this model are objects (home, car etc), personal characteristic (confidence, self esteem, etc), conditions (marital status, seniority, etc) and energies (time, money and knowledge). According to COR theory stress is the individual's reaction to the environment, that occurs when there is either a threat or an actual loss of resources in the environment, and also when the resources gained after investment of resources are not envisioned to be sufficient. COR theory also suggests that an individual under stress due to loss of a resource may utilize his other resources to overcome the loss and reduce the stress. COR theory has been used in work family literature to understand as to how the loss of resources can increase work family conflict, and how an individual with ample resources shall experience lower level of work family conflict. (Grandey \& Cropanzano, 1999) were the first ones to study the work family conflict as interplay between resource gains and lose in accordance with COR theory. Their study argued that work role stressors like work role conflict and ambiguity led to $\mathrm{W} \rightarrow \mathrm{F}$ conflict, because high level of these stressors tap the available resources and an individual under stress due to loss of resource may utilize his other resources to overcome the loss and reduce the stress. COR theory has been used in 
Table 1: Studies on Work Family Conflict of Expatriates

\begin{tabular}{ll}
\hline Author (year) & Title of the Study \\
\hline (Ensher, Grant-Vallone, \& & An examination of work and personal life \\
Donaldson, 2001) & $\begin{array}{l}\text { conflict, organizational support, and and } \\
\text { employee health among international } \\
\text { expatriates. }\end{array}$
\end{tabular}

(Shaffer, Harrison, Gilley, Struggling for balance amid turbulence on \& Luk, 2001) International assignments: work family conflict, support and commitment.

(Shaffer \& Joplin, 2001)

Work-family conflict on international assignments: Time and strain based determinants and performance effort consequences.

(Harris, 2004)

(Shaffer et al., 2004)

Work-family conflict on international assignments: domain-specific and domain-spanning stressors and outcomes

Global careers: Work-life issues and the adjustment of women international managers conflict are likely to increase in international working scenarios. It argues that the boundaries between work and home become more blurred due to the physical relocation of the entire family, causing increasing stress.

Using Human Capital Theory and Conservation of Resource Model the study examines the domain specific and domain spanning antecedents and outcomes of work family conflict of expatriates, with special regard to expatriate related challenges such as adjustment and cultural novelty issues.

Role interference and subjective well being among expatriate families.

(Van der Zee, Ali, \& Salome, 2005)

(Shortland \& Cummins, 2007)

Work-life balance: Expatriates reflect the international dimension.

Work-life balance-a neglected issue among Austrian female expatriates.

(I. C. Fischlmayr \&

Kollinger, 2010)

(Shih, Chiang, \& Hsu, 2010)

(Mäkelä, Suutari, \& Mayerhofer, 2011)

(Schütter \& Boerner, 2013)

(Mäkelä, Lämsä, Heikkinen, \& Tanskanen, 2017)

\section{Focus of the Study}

The study analyzes the effect of the two directions of work family conflict and organizational support on the mental well being of expatriates.

Applying Human Capital Theory, the study investigates the affects of the two directions of work family conflict and perceived organizational support on the withdrawal cognitions of expatriates.

The study examines the antecedents and performance outcomes of the wo directions of work family conflict of expatriates. Long work hours, business travel, time pressure and work adjustment were proposed as parental demands, spousal adjustment and support were investigated as the antecedents of $\mathrm{F} \rightarrow \mathrm{W}$ conflict.

The study investigates the impact of work and family life demands and social support, on the positive and negative work-home and home-work interference.

The survey conducted by ORC Worldwide to understand the issues regarding work life balance of expatriates is examined in this study. It suggests that MNCs need to do more to devise and communicate worklife balance policies that are beneficial to expatriates.

A qualitative research, study focuses on work life balance of female expatriates. The study reveals how leisure time, sport, personal confidence and company support can influence the work life balance of female expatriates.

A quantitative research; the study examines the effects of multinational companies (MNC) implementation of a high involvement work system (HIWS) on work family conflict and performance of expatriates.

family conflict, and performance - examining Taiwanese expatriates in China.

Lives of female expatriates: work-life balance concerns

Illuminating the work-family interface on international assignments: An exploratory approach

Work-to-personal-life conflict among dual and single-career expatriates: Is it different for men and women?
The study examines the role life and career stages play in a female expatriates' worklife conflict and enrichment experiences.

A qualitative research which focused on identifying antecedents of conflict and enrichment among expatriates

Explored difference between men and women as well as dual earner or single earner couples. 
work family literature to understand as to how the loss of resources can increase work family conflict, and how an individual with ample resources shall experience lower level of work family conflict. (Grandey \& Cropanzano, 1999) were the first ones to study the work family conflict as interplay between resource gains and lose in accordance with COR theory. Their study argued that work role stressors like work role conflict and ambiguity led to $\mathrm{W} \rightarrow \mathrm{F}$ conflict, because high level of these stressors tap the available resources and an individual is left with fewer resources for family domain leading to an increase in $\mathrm{W} \rightarrow \mathrm{F}$ conflict. In the same way family role stressors were recognized to cause $\mathrm{F} \rightarrow \mathrm{W}$ conflict, by taking up more than their share of resources.

COR theory also provides space for moderators, contesting that people with more resources can overcome their losses and not feel less stress than the individual with fewer resources. Keeping in view the COR theory Poelmans et al. (2003 Allen, O'Driscoll, and Sanchez 2003) proposed that work resources will moderate the relationship between work demands and $\mathrm{W} \rightarrow \mathrm{F}$ conflict, and family resources will moderate the relationship between family demands and $\mathrm{F} \rightarrow \mathrm{W}$ conflict. That is more resources an individual have less significant will be the relation between increase in demands and work family conflict.

We rely on COR theory for understanding the work family conflict of expatriates due to various reasons. First, COR theory recognizes change, being a series of linked events, as a potential factor contributing to stress. It argues that though change or transitions are not necessarily stressful within themselves, but if an individual faces a threat of or an actual loss of resources due to the challenges associated with the change the stress is more than likely to ensue. Expatriation is a special kind of work role transition which brings changes in both work and family lives of expatriates(Shaffer et al., 2001). We believe that COR theory shall best explain as to how these changes may ensue conditions that threaten the personal resources of expatriate and can lead to an increase in their work family conflict.

Second, COR theory also recognizes social support as a type of resource required to sustain all other resources. This idea of social support helps to understand social support as a vital resource the absence of which can result in either direction of work family conflict and decrease in well being of an individual. Last and most important reason for relying on COR theory to explore the work family conflict of expatriates is that it allows space for moderators. The COR theory suggests that though loss of a resource is stressful, the individuals employ other available resources to offset this loss. These other resources used to cope for the loss of a resource may be the energy resource like time and knowledge or personality characteristics like self esteem, self efficacy and emotional stability (Hobfoll, 1989). We believe that COR theory can best explain the proposition that expatriates with certain personal traits can handle the challenges of expatriation better than others.

\section{$\mathrm{W} \rightarrow \mathrm{F}$ CONFLICT OF EXPATRIATES.}

It is well recognized $\mathrm{W} \rightarrow \mathrm{F}$ conflict arises from the work domain (Carlson \& Kacmar, 2000; Frone, Russell, \& Cooper, 1992a; Gutek, Searle, \& Klepa, 1991). The main challenge that expatriate face in their work domain is that of dealing with the new environment. The major part of expatriate research is related to expatriate work adjustment issues, as it has been find to be related to their withdrawal cognitions. Work adjustment has been measured in terms of expatriate feeling comfortable with and adjusted to his job responsibilities, performance expectations, and his co-workers. A better adjusted expatriate is considered to be less stressed out than his maladjusted compatriots. Work adjustment has been found to be related to withdrawal cognitions and job satisfaction (Black \& Stephens, 1989; Harrison et al., 2004). In the present study however we focus on how the expatriate fits into his new work environment. Person environment fit (PE fit) is defined as the congruence or compatibility between an individual and his environment that occurs when value, goals and characteristics of the two are well matched (Kristof-Brown et al., 2005). Over the last decade there has been a gradual rise in interest in the concept of PE fit. PE fit theory argues that any mismatch between the person and his environment leads to stress, difficulty in social integration and mental strain. On the other hand a perceived match between the person and his environment supposedly leads to improved well being and better social adjustment (Edwards \& Rothbard, 1999). Researchers have recognized four types of PE fits, person organization (PO) fit, person job (PJ) fit, person supervisor (PS) fit, and person-group (PG) fit (Kristof-Brown, et al., 2005). Of the four types of PE fits, we are more concerned with PG and PS fit, as these two have been specifically studied with regards to new comers in a group or an organization. The focus of our study is expatriates who though are not new comers in organizational context, but they do join a new group and have to deal with a new supervisor.

\section{Person Group Fit}

Person group (PG) fit refers to the compatibility between the new hire and his immediate work group ((Werbel \& Gilliland, 1999)). Higher PG fit is known to result in better work relationships and improved social interactions with the co-workers (Werbel \& Johnson, 2001). There are two type of differences that have been recognized by PG fit researchers that can hinder an individual's PG fit; deep level differences described as psychological characteristics that is values, personality, and goals and the "surface level" differences such as demographic factors such as age, sex, ethnicity and marital status. Though initially surface level differences were given importance the focus now has shifted towards the deep level differences; the reason being that deep level differences have significant negative effects on the social integration into a group in short as well as long term, while surface level differences had an effect on in the very initial phase(Harrison, Price, Gavin, \& Florey, 2002). Also Guillaume, Brodbeck, and Riketta (2012)established that surface level differences had negative influence on social integration only under low team interdependence. While deep level diversities had negative influence on social integration under both high and low team interdependence. Keeping in view these finding, we believe that while investigating PG fir the focus should be on the deep level differences.

Defining social capital as trust, social resources, and social network Lee, Reiche, and Song (2010)argues that better PG fit positively influences a newcomers social capital in an organization. On the other hand lower level of PG fit has been found to hinder the social integration of the new comer into a group (Guillaume et al., 2012). Not having the compatibility with new co workers makes it more difficult for the new comer to form social network and support system at work. In work family literature social support is recognized as a significant antecedent of work family conflict. Furthermore according to COR theory social support is one of the most important personal resource an individual requires to gain and contain other resources (Kraimer, Wayne, \& Jaworski, 2001)we believe that lower the perceived PG fit of the expatriates, lower will be their social support/network at work and higher will be the $\mathrm{W} \rightarrow \mathrm{F}$ conflict they face.

Proposition 1. PG fit is negatively related to $\mathrm{W} \rightarrow \mathrm{F}$ conflict of expatriates.

\section{Person Supervisor Fit}

PS fit is concerned with the dyadic relationships between individuals and their supervisors. PS fit occurs when subordinate and supervisor have compatible or common values. Research on PS fit has so far examined subordinate-supervisor value congruence, personality similarity and goal congruence (Kristof-Brown et al., 2005).

Lee et al. (2010) suggests that PS fit positively influences the social capital of a new comer in an organization. Having congruence with the values and goals of the supervisor can provide the new employee better opportunities to socialize. PS fit is important to our study as expatriates on international assignment have to deal with a new supervisor in the 
host country. Having personal goals and values congruence with the new supervisor can help the expatriates to be more comfortable and have better social interactions in their new work environment.

Proposition 2. PS fit is negatively to $\mathrm{W} \rightarrow \mathrm{F}$ conflict of expatriates.

One of the most important questions regarding PE fit is; how to measure it? There are two ways to measure the various types of PE fit; perceived (subjective) and actual (objective). The actual (objective) fit is measured through a comparison between separately rated environmental (organization/job/group/supervisor) and personal characteristics. A perceived fit is the direct assessment of compatibility done by the individual in question. Perceived measurement is considered to be more beneficial by most researchers because as conceptualization good PE fit exists as long as the employee perceives it to exist, disregarding the question as to whether the organization actually compliments the characteristics of the employee(Kristof, 1996). We believe that, for this study also perceived measurement of the PE fit is more relevant. If an expatriate perceives his environment to be in congruence with his needs and goals, he will be more relaxed and feel less strain even if his group or supervisor don't complement his personality or values.

\section{$\mathrm{F} \rightarrow \mathrm{W}$ CONFLICT OF EXPATRIATES}

Apart from the usual issues of family role stressors like conflict and ambiguity expatriates face many distinctive challenges in their family domain as well, which can cause strain and lead to $\mathrm{F} \rightarrow \mathrm{W}$ conflict.

\section{Cultural Novelty}

Cultural novelty is defined as the perceived distance between the national cultures of host and home countries. Higher the cultural novelty being experienced by expatriates more difficult it is for them to get accustomed to the general living environment of the host country. Cultural novelty is recognized as one of the most vital non-work factor that increased "uncertainty" in the lives of expatriates (Mendenhall \& Oddou, 1985). According to Black, Mendenhall, and Oddou (1991) greater the difference between cultures of home and host counties more difficult it is for expatriates to adjust; become comfortable with their host environment.

While relocating to a foreign country the expatriates carry with them the pre conceived notions of appropriate behaviours based on their experiences and learning in their native countries. But these perceptions of how to behave and act in a society more often than not prove to be insufficient because every country has its own set of unique beliefs and values (Harrison, Shaffer, \& Bhaskar-Shrinivas, 2004). If the perceived difference between the host and home countries culture is high, the expatriate's previous knowledge about values and behaviors become irrelevant and they have to learn and adopt the new cultural environment they have come to live in (Stroh, Black, Mendenhall, \& Gregersen, 2004). However if the cultural novelty is high that means that expatriate lose one of their coveted personal resources i.e. appropriate way to behave and act in the social set up, this loss in accordance with COR theory can lead to $\mathrm{F} \rightarrow \mathrm{W}$ conflict.

Mateu (2006) recognized that expatriates considered the learning of the underlying cultural structure of the host country most important and helpful. Underlying structures of a particular culture refers to the elusive aspects of the culture, such as norms, ethics, symbols, and assumptions that have a particular meaning for those that share that culture. It is believed that all this learning the appropriate behaviors and underlying cultural structures of the host country require extra time and effort. Expatriates will have to spend their personal resources like time and energy to gain another resource; the knowledge regarding the host culture.

Proposition 3. Cultural novelty is negatively related to $\mathrm{F} \rightarrow \mathrm{W}$ conflict of expatriates.

\section{Spousal Adjustment}

Spousal or family adjustment is defined as the psychological comfort experienced by the spouse/family of expatriates towards the host country living environment. Black et al. (1991) considered family and especially spousal adjustment as the most important construct having an effect on expatriate adjustment. It is argued that uncertainty and stress that arises due to the lack of cross cultural adjustment of spouses hinders the adjustment of expatriates. Shaffer and Harrison (1998) studied the effect of spouse experiences on the withdrawal cognitions of expatriates. Spouse experiences were assessed using three variables; spousal adjustment, spouses overall satisfaction and perceived living standards. Of these variables spousal adjustment emerged as the most vital negative predictor of withdrawal cognitions of the expatriates. Harrison et al. (2004) while proposing that spousal adjustment is negatively related to $\mathrm{F} \rightarrow \mathrm{W}$ conflict, argued that more adjusted the spouse is in the new living environment, less will be the demands on expatriate's time and energy resources. In other words if the spouses will be well adjusted in their new environment the expatriates will not have to apply extra effort or resources to make them comfortable with the new living conditions. We believe that as spousal adjustment may affect the demands and resource balance between the work and family domains, it is more than likely to have a significant effect on the $\mathrm{F} \rightarrow \mathrm{W}$ conflict of expatriates.

Takeuchi, Yun, and Russell (2002) identified the reciprocal relationship between spouse and expatriate adjustment. More adjusted the spouse is better is the adjustment of expatriates and vice versa. Considering the positive relationship between spousal and expatriate adjustment, Takeuchi, Wang, and Marinova (2005) established that if the spouse is not present physically to provide psychological and logistical support at home the expatriate will have to spend more time at home, which will hinder his work performance and cause strain. This problem was more pronounced when the expatriates were accompanied by children, but not the spouse. The study emphasized the importance of physical presence of spouses during the international assignments. A well adjusted spouse is able to provide better support to the expatriates than a maladjusted one. Support provided by a well adjusted spouse is a vital resource that, in accordance with COR theory can help reduce the stress as well as $\mathrm{F} \rightarrow \mathrm{W}$ conflict of the expatriates.

Proposition 4. Spousal adjustment is negatively related to $\mathrm{F} \rightarrow \mathrm{W}$ conflict of expatriates.

Spousal adjustment can be measured by directly asking the expatriate's spouse to fill in the questionnaires, or expatriate can answer the questions on behalf of their spouses (Shaffer \& Harrison, 1998). For the present study we propose that spousal general and interaction adjustment should be evaluated by spouses themselves.

\section{EXPATRIATE PERSONALITY AS THE MODERATOR}

Interest in the relationship between personality and work related construct has been on the rise since the past several years (Judge, Heller, \& Mount, 2002; Manojlovich \& Laschinger, 2002; Sullivan \& Bhagat, 1992). Many different personality characteristics have been investigated with regard work satisfaction, life satisfaction and work family conflict. However most of the personality related research in recent years is based on the Five Factor Model (FFM) of Personality. The FFM is based on the traits theory of personality; according to which an individual can be characterized in terms of reasonably persisting patterns of thoughts feelings and actions. The FFM asserts that personality traits can be assessed quantitatively, and these traits also exhibit cross-situational consistency up to some extent.

The five personality traits as recognized by FFM are openness to experience, conscientiousness, extraversion, agreeableness, and emotional stability (McCrae \& John, 1992). These personality traits have been studied as a moderator between the work family conflict and its outcomes. In the present study we shall discuss and propose as to how the personality traits can be a resource for expatriates moderating the relationship between expatriate related work and family role 
stressors and the subsequent work family conflict. Of the five personality traits of FFM model, we will be focusing on two; openness to experience and extraversion as these have been repeatedly found to facilitate expatriates in their social integration and adjustment.

\section{Openness to experience}

Openness to experience is a trait that refers to characteristics such as imagination, curiosity, and innovativeness. Kinnunen, Vermulst, Gerris, and Mäkikangas (2003) suggests that individuals with this trait may be able to use their imagination to find new ways to balance their work and family lives. Openness to experience has been found to be positively related to an expatriate's work adjustment (T.-J. Huang, Chi, \& Lawler, 2005) Studying expatriates, (Caligiuri, 2000) study found that openness to experience moderates the relationship between contact with host country nationals and cross-cultural adjustment.

People who are high in openness enjoy new experiences and like to learn new things (Costa Jr \& McCrae, 1992). In case of expatriates this trait helps them to understand the behaviour, values and attitudes of the host country nationals in a better way. Furthermore the characteristic of not being very rigid in their view of right and wrong helps expatriates to be more accepting of the host country's culture. It is more than probable that expatriates who are open to experiences will be more understanding of the cultural novelty (Hsu \& Huang, 2016), and shall be able to undermine the strain stemming from it that can lead to work family conflict. Similarly openness to experience can also prove to be the resource that can help expatriates to accept and empathize with any incompatibility of their personalities, goal and values with those of their group members or supervisors. This characteristic thus may help expatriates in overcome the absence of PS or PG fit, or high cultural novelty, experiencing less level of stress leading to reduced work family conflict.

Proposition 5. Open to experiences moderates the relationships between a) organizational cultures Novelty and $\mathrm{W} \rightarrow \mathrm{F}$ conflict of expatriates b) work role novelty and the $\mathrm{W} \rightarrow \mathrm{F}$ conflict of expatriates.

Proposition 6. Open to experiences moderates the relationships between a) spousal adjustment and $\mathrm{F} \rightarrow \mathrm{W}$ conflict of expatriates $\mathrm{b}$ ) cultural novelty and $\mathrm{F} \rightarrow \mathrm{W}$ conflict of expatriates c) satisfaction regarding educational facilities and $\mathrm{F} \rightarrow \mathrm{W}$ conflict.

\section{Extraversion}

Extraversion refers to the level of sociability; individuals high in extraversion enjoy the company of others (Costa Jr \& McCrae, 1992). In work family literature Dijkstra, van Dierendonck, Evers, and De Dreu (2005) reveals that effects of conflict at work were more pronounced on well being of individuals with low extraversion. In expatriate literature it has been found that extravert expatriates are better at social interactions and get better adjusted in their general environment than the expatriates who score low in extraversion (Shaffer, Harrison, Gregersen, Black, \& Ferzandi, 2006). Better adjustment means expatriates are not stressed out but comfortable in their environment and have more resources to spare and thus experience less $\mathrm{F} \rightarrow \mathrm{W}$ conflict than their compatriots. Extrovert expatriates aspire to interact and communicate with host country nationals to understand the host country's culture. This trait can surely help expatriate reduce the high cultural novelty and subsequently decrease $\mathrm{F} \rightarrow \mathrm{W}$ conflict.

Moreover extravert individuals get energized by interacting with other people; they are capable of achieving their goals by navigating through their social environment (Costa Jr \& McCrae, 1992). We believe that this trait of successfully navigating through social environment can be the resource that can greatly help expatriate to overcome the values and goals congruence issues with their supervisor or group. We propose that relationship between strain of lack of PG and PS fit and the work family conflict of expatriates will be less pronounced for extravert expatriates than the ones lacking extraversion. Thus we propose,

Proposition 7. Extraversion moderates the relationships between a) PG fit and $\mathrm{W} \rightarrow \mathrm{F}$ conflict of expatriates b) PS fit and $\mathrm{W} \rightarrow \mathrm{F}$ conflict of expatriates

Proposition 8. Extraversion moderates the relationships between a) spousal adjustment and $\mathrm{F} \rightarrow \mathrm{W}$ conflict of expatriates b) cultural novelty and $\mathrm{F} \rightarrow \mathrm{W}$ conflict of expatriates.

\section{Reciprocal relationship between $\mathrm{W} \rightarrow \mathrm{F}$ and $\mathrm{F} \rightarrow \mathrm{W}$ conflict}

Frone, Russell, and Cooper (1992a) proposed and tested a model for the US employees and established that there exists a "positive and reciprocal" relationship between $\mathrm{W} \rightarrow \mathrm{F}$ conflict and $\mathrm{F} \rightarrow \mathrm{W}$ conflict. Aryee, Fields, and Luk (1999) tested Frone, et al.'s (1992) model for Hong Kong employees and their results further validated the existence of positive reciprocal relationship between $\mathrm{W} \rightarrow \mathrm{F}$ conflict and $\mathrm{F} \rightarrow \mathrm{W}$ conflict. The existence of the positive reciprocal relationship means an increase in one signifies an increase in the other. However, the intensity with which $\mathrm{W} \rightarrow \mathrm{F}$ conflict influences $\mathrm{F} \rightarrow \mathrm{W}$ conflict may be different from the strength with which $\mathrm{F} \rightarrow \mathrm{W}$ conflict affects $\mathrm{W} \rightarrow \mathrm{F}$ conflict depending on the cultural values of the selected sample (Aryee, et. al., 1999). The positive reciprocal relationship is best understood by taking into account the spillover theory. $\mathrm{W} \rightarrow \mathrm{F}$ conflict that causes family demands to go unfulfilled gives rise to family issues and in accordance with spillover theory these family issues spillover into the work domain, causing family to interfere with work that is giving rise to $\mathrm{F} \rightarrow \mathrm{W}$ conflict (Carlson \& Kacmar, 2000).

To the best of our knowledge there is no study yet which investigates the strength of the reciprocal relationship between the two directions of the conflict for expatriates. We believe it is vital to investigate the reciprocal relationship between the two forms of conflict for expatriates because work domain antecedents of $\mathrm{W} \rightarrow \mathrm{F}$ conflict can influence the $\mathrm{F} \rightarrow \mathrm{W}$ conflict of expatriates due to the existence of the positive reciprocal relationship between the two forms of conflict (Boyar, Maertz Jr, Pearson, \& Keough, 2003)and vice versa. Most of the expatriate studies regarding work life balance of expatriates tend to be "unidirectional", that is they focus mostly on how the family demands and issues are affecting the work life and performance of expatriates (Shaffer, et al., 2001). According to Heraty, Morley, and Cleveland (2008) when it comes to expatriates work family interface literature the perspective of the expatriate family is almost completely missing. While investigating the work family linkages for expatriate's researchers have mainly focused on how expatriates family related issues may influence their work performance. There are numerous studies which investigate as to how general and spousal adjustment of an expatriate may affect the work adjustment of the expatriate (Takeuchi, et al., 2005; Shaffer \& Harrison, 1998), but the perspective of the family as to how work related strains and work adjustment may have an effect on an expatriates family life is almost missing from the expatriate literature.

We believe investigating the direction and strength of relationship between the two forms of conflict helps in getting a holistic picture and understanding whether $\mathrm{W} \rightarrow \mathrm{F}$ conflict is stronger or $\mathrm{F} \rightarrow \mathrm{W}$ conflict has more influence. By investigating the positive reciprocal relationship we will be able to comprehend as to whether the work related strains can cause the family interference with work to escalate due to the spill over affect, or is it the family domain issues that are stronger and cause a very strong $\mathrm{F} \rightarrow \mathrm{W}$ that leads to an increase in $\mathrm{W} \rightarrow \mathrm{F}$ conflict of expatriates. As to the best of our knowledge the relation between the two directions of work family conflict has not been studied for expatriates, for this study we propose the basic hypothesis, Proposition 9. There exists a positive and reciprocal relationship between $\mathrm{F} \rightarrow \mathrm{W}$ conflict and $\mathrm{W} \rightarrow \mathrm{F}$ conflict of expatriates. 


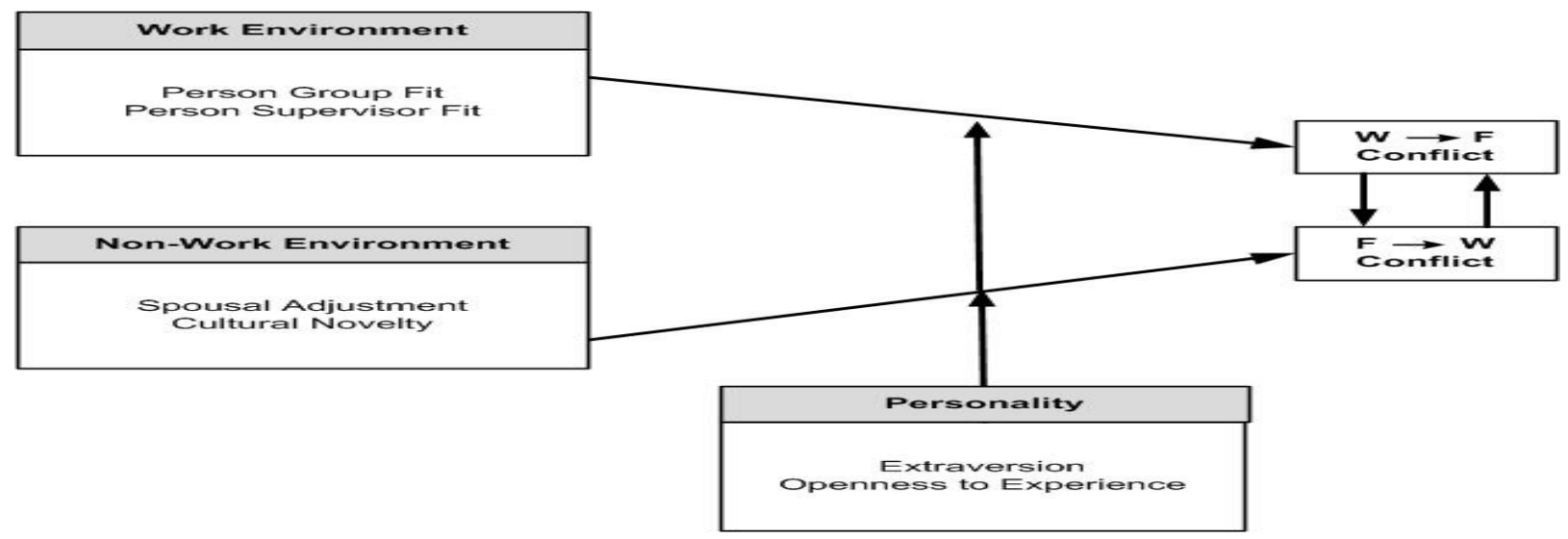

Fig. 1. Work Family Conflict of Expatriates: Its Antecedents and Moderators

\section{DISCUSSION AND CONCLUSION}

The present study investigates one of the least explored areas of expatriate literature: their work family conflict. Today work attitudes and priorities are changing, with younger generation giving more value to their work life balance than to their careers (I. C. Fischlmayr \& I. Kollinger, 2010). Keeping in view the changing priorities of the work force the research in the domain of work life balance is on a study increase. Expatriates are one of the most significant employees when it comes to the workforce of an MNC. According to GRTS (2011), the 120 MNCs surveyed on average earned $58 \%$ of their revenue from their overseas operations. In order to establish themselves globally MNCs need competent expatriates to perform well on their international assignments(Stevens, Oddou, Furuya, Bird, \& Mendenhall, 2006). Work family conflict of an individual not only has negative influence on his personal life but also leads to negative outcomes for the organizations in terms of absenteeism and loss of vital employees(Wayne, Lloyd, Dunn, \& Hammer, 2003). Considering the significance of expatriate assignments and the fact that a large majority of expatriates face work family balance issues (ORC Worldwide, 2007), it is imperative to recognize and contain the factors that may contribute to the expatriates' work family conflict.

The present study provides a theoretical framework regarding the affects work and non-work related challenges faced by expatriates, during their assignments, may have on their work family conflict. It applies COR model to understand how the loss or gain of resources in work and family domains can affect the work-life balance of expatriates. The study argues that considering they influence the social integration and network building of an individual, PG and PS fit of an expatriate can very well have an impact on their $\mathrm{W} \rightarrow \mathrm{F}$ conflict. This is a new concept, PG and PS fit have been related to new comers in PE literature but has not been studied yet with regard to social integration and strain issues of expatriates who though are not newcomers in the organization but do join a new group and have a new supervisor. Moreover keeping in view the COR model the study suggests that high cultural novelty and spousal maladjustment both signify loss of personal resources and can lead to $\mathrm{F} \rightarrow \mathrm{W}$ conflict.

Personality traits, openness to experience and extraversion, have been proposed to moderate the relationship between work and family domain stressors and the subsequent work family conflict. One of the important selection criteria used by MNCs while screening candidates for an international assignment is the personal traits of the candidates. Understanding as to which personality traits are more helpful to expatriates into handling the stress of expatriation and reducing their work family conflict, can be very useful for their MNCs. The study also takes the first step towards understanding the strength of the relationship between the two directions of work family conflict of expatriates. It will surely help in understanding as to if in actual the family domain issues are more significant and have a major influence on an expatriates work life as visualized by most expatriate studies, or is there another side of this picture.

The paper nonetheless presents a model based on previous studies and empirical evidence and it surely requires empirical testing of its own to draw substantial results. To fully investigate the specific issues that expatriates face, which can increase their work family conflict the paper calls for a quantitative study. The results of the quantitative investigation will provide a detailed view of the challenges of the international assignments that can disturb the work life balance of expatriates and increase their work family conflict. The findings will form the basis of an integrative model of work family conflict of the expatriates and shall help MNCs in devising effective policies to deal with the work-life balance issues of their international assignees.

\section{REFERENCES}

Aryee, S., Fields, D., \& Luk, V. (1999). A cross-cultural test of a model of the work-family interface. Journal of Management, 25(4), 491-511.

Black, J. S., Mendenhall, M., \& Oddou, G. (1991). Toward a comprehensive model of international adjustment: An integration of multiple theoretical perspectives. Academy of Management Review, 16(2), 291-317.

Boyar, S. L., Maertz Jr, C. P., Pearson, A. W., \& Keough, S. (2003). Workfamily conflict: A model of linkages between work and family domain variables and turnover intentions. Journal of managerial Issues, 175-190.

Brynningsen, G. (2009). Managing expatriates on international assignments. Otago Management Graduate Review, 7, 1-17.

Caligiuri, P. M. (2000). The big five personality characteristics as predictors of expatriate's desire to terminate the assignment and supervisor-rated performance. Personnel psychology, 53(1), 67-88.

Costa Jr, P. T., \& McCrae, R. R. (1992). Four ways five factors are basic. Personality and Individual differences, 13(6), 653-665.

Cuizon, G. (2009). Expatriates in international assignments: Types and strategic reasons for expatriation. Retrieved from http://www.suite101.com/content/expatriates-in-internationalassignments-a 94403

Dijkstra, M. T., van Dierendonck, D., Evers, A., \& De Dreu, C. K. (2005). Conflict and well-being at work: the moderating role of personality. Journal of Managerial Psychology, 20(2), 87-104.

Ensher, E. A., Grant-Vallone, E. J., \& Donaldson, S. I. (2001). Effects of perceived discrimination on job satisfaction, organizational commitment, organizational citizenship behavior, and grievances. Human Resource Development Quarterly, 12(1), 53-72.

Fischlmayr, I., \& Kollinger, I. (2010). Work-life balance-a neglected issue among Austrian female expatriates. The International Journal of Human Resource Management, 21(4), 455-487.

Fischlmayr, I. C., \& Kollinger, I. (2010). Work-life balance-a neglected issue among Austrian female expatriates. The International Journal of Human Resource Management, 21(4), 455-487.

Frone, M. R. (2003). Work-family balance. Washington, DC: American Psychological Association.

Frone, M. R., Russell, M., \& Cooper, M. (1992a). Antecedents and outcomes of work-family conflict: Testing a model of the work-family interface. 
Journal of Applied Psychology, 77(1), 65-78. 10.1037/00219010.77.1.65

Grandey, A., \& Cropanzano, R. (1999). The conservation of resources model applied to work-family conflict and strain. Journal of Vocational Behavior, 54(2), 350-370.

Guillaume, Y. R., Brodbeck, F. C., \& Riketta, M. (2012). Surface-and deeplevel dissimilarity effects on social integration and individual effectiveness related outcomes in work groups: A meta-analytic integration. Journal of Occupational and Organizational Psychology, 85(1), 80-115.

Harris, H. (2004). Global careers: Work-life issues and the adjustment of women international managers. Journal of Management Development, 23(9), 818-832.

Harrison, D. A., Price, K. H., Gavin, J. H., \& Florey, A. T. (2002). Time, teams, and task performance: Changing effects of surface-and deep-level diversity on group functioning. Academy of management journal, 45(5), 1029-1045.

Harrison, D. A., Shaffer, M. A., \& Bhaskar-Shrinivas, P. (2004). Going places: Roads more and less traveled in research on expatriate experiences. In Research in personnel and human resources management (pp. 199-247): Emerald Group Publishing Limited.

Heraty, N., Morley, M. J., \& Cleveland, J. N. (2008). Complexities and challenges in the work-family interface. Journal of Managerial Psychology, 23(3), 209-214.

Hofstede, G. (1983). The cultural relativity of organizational practices and theories. Journal of international business studies, 14(2), 75-89.

Hsu, C. H., \& Huang, S. S. (2016). Reconfiguring Chinese cultural values and their tourism implications. Tourism Management, 54, 230-242.

Huang, T.-J., Chi, S.-C., \& Lawler, J. J. (2005). The relationship between expatriates' personality traits and their adjustment to international assignments. The International Journal of Human Resource Management, 16(9), 1656-1670.

Huang, Y., Hammer, L., Neal, M., \& Perrin, N. (2004). The relationship between work-to-family conflict and family-to-work conflict: A longitudinal study. Journal of Family and Economic Issues, 25(1), 79-100.

Judge, T. A., Heller, D., \& Mount, M. K. (2002). Five-factor model of personality and job satisfaction: A meta-analysis. Journal of applied psychology, 87(3), 530.

Kahn, R. L., Wolfe, D. M., Quinn, R. P., Snoek, J. D., \& Rosenthal, R. A. (1964). Organizational stress: Studies in role conflict and ambiguity. New York: John Wiley.

Kinnunen, U., Vermulst, A., Gerris, J., \& Mäkikangas, A. (2003). Work-family conflict and its relations to well-being: The role of personality as a moderating factor. Personality and Individual differences, 35(7), 1669-1683.

Kraimer, M. L., Wayne, S. J., \& Jaworski, R. A. A. (2001). Sources of support and expatriate performance: The mediating role of expatriate adjustment. Personnel psychology, 54(1), 71-99.

Kristof-Brown, A. L., Zimmerman, R. D., \& Johnson, E. C. (2005). Consequences of individuals' fit at work: a meta-analysis of personjob, person-organization, person-group, and person-supervisor fit. Personnel psychology, 58(2), 281-342.

Kristof, A. L. (1996). Person-organization fit: An integrative review of its conceptualizations, measurement, and implications. Personnel psychology, 49(1), 1-49.

Lee, Y.-t., Reiche, B. S., \& Song, D. (2010). How do newcomers fit in? The dynamics between person - environment fit and social capital across cultures. International Journal of Cross Cultural Management, 10(2), 153-174.

Mäkelä, L., Lämsä, A.-M., Heikkinen, S., \& Tanskanen, J. (2017). Work-topersonal-life conflict among dual and single-career expatriates: Is it different for men and women? Journal of Global Mobility, 5(3), 304316.

Mäkelä, L., Suutari, V., \& Mayerhofer, H. (2011). Lives of female expatriates: work-life balance concerns. Gender in Management: An International Journal, 26(4), 256-274.

Manojlovich, M., \& Laschinger, H. K. S. (2002). The relationship of empowerment and selected personality characteristics to nursing job satisfaction. Journal of nursing administration, 32(11), 586-595.

Mateu, M. (2006). Reflexivity as a Facilitator to Adjusting to a New Culture. International Journal of Learning, 12(12).

McCrae, R. R., \& John, O. P. (1992). An introduction to the five-factor model and its applications. Journal of personality, 60(2), 175-215.

Mendenhall, M., \& Oddou, G. (1985). The dimensions of expatriate acculturation: A review. Academy of Management Review, 10(1), $39-47$.
Poelmans, S., Spector, P. E., Cooper, C. L., Allen, T. D., O'Driscoll, M., \& Sanchez, J. I. (2003). A Cross-National Comparative Study of Work/Family Demands and Resources. International Journal of Cross Cultural Management, 3(3), 275-288. $10.1177 / 1470595803003003002$

Schütter, H., \& Boerner, S. (2013). Illuminating the work-family interface on international assignments: An exploratory approach. Journal of Global Mobility: The Home of Expatriate Management Research, 1(1), 46-71.

Shaffer, M. A., \& Harrison, D. A. (1998). Expatriates' psychological withdrawal from international assignments: work, nonwork, and family influences. Personnel psychology, 51(1), 87-118.

Shaffer, M. A., Harrison, D. A., Gilley, K. M., \& Luk, D. M. (2001). Struggling for balance amid turbulence on international assignments: Workfamily conflict, support and commitment. Journal of Management, 27(1), 99-121.

Shaffer, M. A., Harrison, D. A., Gregersen, H., Black, J. S., \& Ferzandi, L. A. (2006). You can take it with you: Individual differences and expatriate effectiveness. Journal of applied psychology, 91(1), 109.

Shaffer, M. A., Harrison, D. A., \& Joplin, J. R. (2004). Work-family conflict on international assignments: Domain-specific and domain-spanning stressors and outcomes: Business Research Centre, School of Business, Hong Kong Baptist University.

Shaffer, M. A., \& Joplin, J. R. (2001). Work-family conflict on international assignments: time-and strain-based determinants and performance effort consequences. Paper presented at the Academy of Management Proceedings.

Shih, H.-A., Chiang, Y.-H., \& Hsu, C.-C. (2010). High involvement work system, work-family conflict, and expatriate performanceexamining Taiwanese expatriates in China. The International Journal of Human Resource Management, 21(11), 2013-2030.

Shortland, S., \& Cummins, S. (2007). Work-life balance: Expatriates reflect the international dimension. Global Business and Organizational Excellence, 26(6), 28-42.

Stevens, M. J., Oddou, G., Furuya, N., Bird, A., \& Mendenhall, M. (2006). HR factors affecting repatriate job satisfaction and job attachment for Japanese managers. The International Journal of Human Resource Management, 17(5), 831-841.

Stroh, L., Black, J., Mendenhall, M., \& Gregersen, H. (2004). Repatriating: Helping people readjust and perform. International assignments: An integration of strategy, research, \& practice, 189 À217.

Sullivan, S. E., \& Bhagat, R. S. (1992). Organizational stress, job satisfaction and job performance: where do we go from here? Journal of Management, 18(2), 353-374.

Takeuchi, R., Wang, M., \& Marinova, S. V. (2005). Antecedents and consequences of psychological workplace strain during expatriation: A cross-sectional and longitudinal investigation. Personnel psychology, 58(4), 925-948.

Takeuchi, R., Yun, S., \& Russell, J. E. (2002). Antecedents and consequences of the perceived adjustment of Japanese expatriates in the USA. International Journal of Human Resource Management, 13(8), $1224-1244$

Van der Zee, K. I., Ali, A. J., \& Salome, E. (2005). Role interference and subjective well-being among expatriate families. European Journal of Work and Organizational Psychology, 14(3), 239-262.

Wayne, W., Lloyd, M. A., Dunn, D., \& Hammer, E. (2003). Psychology Applied to Modern Life: Adjustment in the 21 st century. In: Belmont, Calif.: Wadsworth/Thomson Learning.

Werbel, J. D., \& Gilliland, S. W. (1999). Person-environment fit in the selection process.

Werbel, J. D., \& Johnson, D. J. (2001). The use of person-group fit for employment selection: A missing link in person-environment fit. Human Resource Management: Published in Cooperation with the School of Business Administration, The University of Michigan and in alliance with the Society of Human Resources Management, 40(3), 227-240.

Whitehead, D. L. (2008). Historical trends in work-family: The evolution of earning and caring. In K. Korabik, D. S. Lero, \& D. L. Whitehead (Eds.), Handbook of Work-Family Integration: Research, Theory, and Best Practices (1 ed.): Academic Press.

Zeeshan, T. (2010). Bi-directional Work Family Conflict and Well being of Expatriates. University Sain Malaysia. Penang. 